\title{
REFLEXIONES DE CLÉRIGOS Y FRAILES SOBRE LAS DEPORTACIONES INDÍGENAS EN LA CONQUISTA DEL PARAGUAY ENTRE 1542 Y 1575
}

\author{
REFLECTION OF CLERGYMEN AND FRIARS ABOUT INDIGENOUS \\ DEPORTATIONS IN THE CONQUEST OF PARAGUAY BETWEEN 1542 AND 1575
}

\author{
Guillaume Candela ${ }^{1}$
}

\begin{abstract}
En los intercambios epistolares entre el Nuevo Mundo y la metrópoli se hizo muy pronto referencia a las deportaciones indígenas, también llamadas rancheadas en la Provincia del Paraguay, que se realizaron en la América colonial. Las denuncias de los malos tratos infligidos a los indígenas del continente exacerbadas por algunos miembros de la Iglesia, tuvieron como consecuencia la aparición de nuevas reglamentaciones promulgadas por la Corona. En la Provincia del Paraguay, a pesar de la ausencia de riquezas minerales, se desarrolló una práctica descontrolada del servicio indígena. Dentro de las múltiples y muy variadas quejas de los eclesiásticos, destaca la práctica de las rancheadas. Este artículo estudia este fenómeno poniendo de realce sus causas y consecuencias en el desarrollo de la conquista de la Provincia del Paraguay entre 1541 y 1575.
\end{abstract}

Palabras claves: cuñadazgo, rancheadas, esclavitud, conquistadores, Paraguay.

The indigenous deportations in the colonial America, also known as rancheadas in the Province of Paraguay, appeared very soon in the epistolary exchanges between the New World and the mother country. The vehement denunciation of the mistreatment of the natives of the continent by some members of the Church, including Brother Bartolome de las Casas, led to a set of new regulations by the Crown. In the Province of Paraguay, despite the absence of mineral wealth, an uncontrolled practice of indigenous service developed. Among the multiple and very diverse complaints of the priests stands out the practice of rancheadas. This paper discusses this practice highlighting its causes and consequences during the conquest of the Province of Paraguay between 1541 and 1575.

Key words: cuñadazgo, rancheadas, slavery, conquistadors, Paraguay.

Los términos y los conceptos de deportaciones y exterminio se refieren generalmente a un sombrío periodo del siglo XX. Sin embargo estos procesos también se verifican en otros momentos históricos. En efecto, nuestras fuentes primarias dan cuenta de múltiples casos de deportaciones indígenas en el Paraguay del siglo XVI. Aunque no todos los desplazamientos indígenas fueron resultado de la conquista española, ya que hubo otros factores en juego, fue la presión colonial la que afectó mayormente a los indígenas marcando cambios rotundos en sus modos de vida.

A continuación analizaremos los primeros contactos entre los españoles y las comunidades indígenas en el contexto socio-histórico de la conquista del Paraguay y examinaremos los procesos de deportación indígena poniendo de manifiesto las lógicas coloniales. Para ello, en la primera parte nos enfocaremos en el proceso de cuñadazgo para contextualizar la praxis de la saca de mujeres indígenas. En una segunda parte, estudiaremos el concepto colonial de rancheadas o deportación masiva de indios a la ciudad de Asunción, apoyándonos en los diferentes testimonios de la época. En una última parte, reflexionaremos sobre las consecuencias que tuvieron las rancheadas para todos los actores de la conquista del Paraguay.

Antes de entrar en el estudio propiamente dicho quisiéramos introducir una cita del conquistador Francisco Ortiz de Vergara quien gobernó la provincia del Paraguay entre 1558 y 1564. En un intercambio epistolario con el padre Martín González,

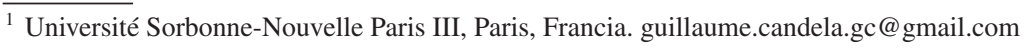


el conquistador dio su parecer en cuanto a la situación indígena del Paraguay de aquel entonces:

Los yndios naturales desta tierra y provinçia no tienen oro ny plata ny cosa alguna de provecho ny dan ny contribuyen mas de con el serviçio personal [...] ellos son en si floxos y poco ynclinados a travajos, comedores de carne umana, enemigos de todas las generaçiones [...] Como se les puede tasar tributos si no tienen de que ny siendo jente de razon porque nynguno ay que sepa contar arriba de cinco lo qual es diferente en la nueva españa y peru que los yndios naturales de aquellos reynos son gente de mucha razon y nacieron sirviendo y contribuyendo a sus prinçipales y señores (M. González 1558).

Esta interesante cita es bastante representativa del conquistador del Paraguay en el siglo XVI en cuanto a las costumbres indígenas, aunque en otras ocasiones también condena los principales defectos de los conquistadores americanos, como el afán de lucro.

\section{Del Cuñadazgo a las Rancheadas}

Los términos de cuñadazgo y de rancheada fueron recuperados o creados como conceptos por los estudiosos del Paraguay colonial con el objetivo de referirse a los primeros contactos hispano-indígenas en la mitad del siglo XVI. Estas nociones pretenden enfatizar dos momentos históricos del proceso de conquista de la Provincia del Paraguay.

El neologismo cuñadazgo parece surgir por primera vez en una carta anónima redactada por un padre jesuita en 1620 , refiriéndose a la creación en 1537 del primer asentamiento español en el río Paraguay, la ciudad de Nuestra Señora de la Asunción:

La fundación de esta ciudad fue mas por via de cuñadasgo, que de conquista porque navegando los españoles por el rio Paraguay arriba [...] respondieron los indios que no passassen adelante porque les pareçia buena gente; y assi les darían sus hijas y serian parientes. Pareçio bien este recaudo a los españoles, quedáronse aqui. reçibieron las hijas de los indios y cada español tenia buena cantidad (Cortesão 1951:163).

El religioso tradujo, a partir de las relaciones y cartas de los primeros conquistadores, un concepto político indígena guaraní basado en las relaciones de parentesco. Para los caciques guaraníes, el don de mujeres a los españoles transformaba al recién llegado en cuñado o en yerno lo que beneficiaba a los dos actores del proceso. De los primeros intercambios hispano-guaraní nacieron a la vez una interdependencia y una servidumbre indígena que se ven condensadas en el concepto de rancheada. En efecto, el procedimiento de cuñadazgo desarrollado entre 1537 y 1541 , estableció por consiguiente una relación de parentesco con los diferentes caciques de la región de Asunción. En la historia guaraní el año de 1541 es un momento clave ya que se decide el abandono del pueblo de Buenos Aires y pues la conversión de Asunción en ciudad y centro de la conquista de la Provincia del Río de la Plata. La implantación del sistema colonial español en Asunción, la creación del cabildo y la publicación de diferentes bandos para vigilar y controlar la naciente sociedad, operaron ya desde 1541 un cambio en las relaciones hispano-indígenas. A partir de esta fecha, la oferta de hijas o de mujeres vinculadas directamente con la familia de los caciques regionales no pudo satisfacer la demanda española. El proceso de cuñadazgo desaparece dejando entre los caciques guaraníes un sentimiento de total sometimiento al poder de algunos familiares. Para desarrollar la idea citaremos a una de las pioneras de la etnohistoria del Paraguay, Branislava Susnik:

$\mathrm{Y}$ al hacer el pacto con los españoles, estableciendo relaciones pacíficas de tovayá, los avá deseaban ser tratados por los karaí como verdaderos avá, vale decir como hombres y como tovayá, vale decir como verdaderos parientes. En cambio comenzaban a manifestarse ya los malos tratos y la violencia por parte de los españoles contra los guaraníes, lo que creaba en éstos un sentimiento de inferioridad, sintiendose tratados como seres inferiores, como tapi'í, como gente menor (Susnik 2011:88).

El término de cuñadazgo se vuelve aún más interesante para nuestro estudio si le atribuimos una raíz lingüística guaraní. En efecto, el proceso de cuñadazgo podría perfectamente derivar de la palabra española cuñado y del substantivo guaraní kuña $\tilde{a}^{1}$ que según la obra Arte de la lengua guaraní del jesuita Antonio Ruiz de Montoya significa mujer.

Por su parte, la voz rancheadas no parece ser un término que emane de las fuentes primarias del siglo XVI, aunque diferentes expresiones tienen como raíz el término substantivo rancho: ranchear, andar rancheando, rancheamiento, estar rancheado... El concepto de rancheadas, que manejan los historiadores y etnólogos del Paraguay colonial, 
derivan del término rancherías que remite a la deportación masiva de mujeres indígenas.

Quisiéramos desarrollar la reflexión sobre el paso del primer al segundo proceso en el Paraguay de la conquista. El proceso de cuñadazgo tuvo muchas consecuencias en las relaciones geopolíticas. Entre 1537 y 1580 las fuentes nos desvelan una verdadera jerarquía entre los indios carios o guaraníes de Asunción y las demás comunidades indígenas. A través de los diferentes interrogatorios indígenas, observamos que el grupo cario-guaraní parecía imponerse en el entramado geopolítico regional, tal como se identifica claramente en el interrogatorio siguiente:

ya se save que preguntando a los yndios Agazes que porque daban sus mugeres a los yndios Caryos respondieron que porque dezian los yndios Caryos que ellos heran los rrezios y que les diesen a ellos sus mugeres porque a nosotros pues nos mataryan (Anónimos 1545).

Vislumbramos aquí una clara dominación y una imposición coercitiva por parte de los indios cariosguaraníes sobre la comunidad indígena de los agazes siempre temida en la época colonial por españoles. Gracias a la información transmitida por el indio agazes interrogado deducimos que la superioridad de un determinado grupo humano influye en el don de mujeres, o sea que el proceso de cuñadazgo define de cierto modo la dominación de una comunidad sobre otra. La comunidad dominada siempre aspira a entrar en relación de parentesco con el grupo dominante para sobrevivir según el testigo Agazes. Trasparece en los documentos una situación muy complicada por parte de los indios agazes frente a la llegada de los nuevos Karaí. En este juego de relaciones de parentesco, los agazes tendrán, a partir de 1541, que satisfacer tanto sus antiguos dueños, los carios-guaraníes, como al nuevo grupo dominante regional, los españoles. Así podría pensarse que muy rápidamente las comunidades indígenas que disponían de poco poder en la provincia del Paraguay, se vieron cada vez más marginadas y perdieron su influencia en esta nueva red de intercambios y de relaciones humanas. El testigo e intérprete español Juan de Fustes advirtió, en su testimonio redactado en los años de 1545-1546, esa nueva realidad que afectó muchos grupos indígenas de la provincia:

ansi mysmo los Agazes e otras generaçiones benyan a tratar e rescatar a esta dicha çibdad con los cristianos como amygos espeçialmente los Agazes por aber dado yndios de su generaçion para que los sirviesen (J. Perez siglo XVI).
El ejemplo de los indios Agazes es esclarecedor: entendiendo la gran influencia de los nuevos karaí, las comunidades dominadas por la comunidad carioguaraní tuvieron que rendirse a los españoles y, por consiguiente perder aún más sus fuerzas procreadoras. De allí se desencadenó ya a partir de 1541 un proceso de extinción de las comunidades indígenas en Paraguay. Habiendo contextualizado el proceso del cuñadazgo insertándolo en el entramado geopolítico de aquel entonces, enfoquémonos más específicamente ahora en el mayor proceso de deportación indígena: las rancheadas.

\section{Deportaciones de Indios Rancheados o Sacados de sus Pueblos Originarios}

Las rancheadas fueron sin ninguna duda el fenómeno de aculturación más efectivo de la conquista. Pueblos enteros fueron vaciados de sus fuerzas procreadoras, marcando así un trauma evidente en la vida de los indios afectados. Dentro del corpus manejado se destaca un religioso que se lanzó en una cruzada contra esta práctica y obró por la defensa de las Indias, y del elemento vernáculo en general, en la historiografía esto le valdrá al clérigo Martín González el apodo del Fray Bartolome de las Casas del Paraguay.

\section{Las rancheadas de mujeres indias}

Encontramos en el estudio realizado por Florencia Roulet en 1993, una hipótesis muy acertada sobre el inicio de las rancheadas, ella señaló un nuevo parámetro para entender el fenómeno:

No olvidemos que con la llegada del adelantado Cabeza de Vaca, en 1542, la población europea de Asunción casi se triplicó, pasando de unos trescientos a cerca de novecientos hombres, con lo que aumentó también proporcionalmente la necesidad de alimentos y de mujeres indígenas que realizaran las tareas domésticas (Roulet 1993:186).

La expedición de Alvar Núñez Cabeza de Vaca en 1542 y la conversión de Asunción en ciudad y centro de la conquista de la Provincia del Río de la Plata en 1541 operaron un cambio sustancial en la demografía regional y en el establecimiento español definitivo en la zona asunceña. Las rancheadas fueron una de las consecuencias del asentamiento español en esta zona del territorio y las mujeres carios-guaraníes fueron las primeras en sufrir una deportación masiva en Paraguay. Un testimonio descriptivo del proceso se encuentra en un documento redactado en 1575 por el clérigo Martín González: 
Los españoles acordaron de caminar de noche por la tierra y de dia estar escondidos hasta ponerse en las fuentes de agua adonde las viejas avian de venir antes que amaneçiesse, porque no los viessen. y quando las viejas venian por agua salian a ellas y echavanles mano y davanles de palos y azotes hasta que dezian y nombravan todas las mugeres que avia en aquel pueblo, y como se dezian e hijas de quien eran. y llevavan tinta y papel, y escrivian lo ansi, y despues llevavan la vieja al prinçipal [...] porque el caçique no lo pudiesse negar, y en leyendole al caçique la memoria y mas la vieja que lo dezia, no lo negava y allende desto echavanle unos grillos que llevavan, y ansi el caçique mandava traer todas aquellas yndias que le leyan (M. González, 3 mayo 1575).

El testimonio presenta una praxis terriblemente eficaz, valiéndose de estratagemas, de amenazas de todo carácter para llegar a sus desastrosos fines. Los robos de seres humanos pudieron llegar a tener una muy alta responsabilidad en la caída demográfica de los pueblos indígenas guaraníes de la zona aunque el ocaso de multitud de pueblos resulta difícil de analizar. Cabe resaltar que las cifras avanzadas por Martín González parecen exageradas, tenemos un primer ejemplo en el que habla del robo de 50.000 mujeres (M. González, 1556) en un lapso de tiempo de 11 años. Veinte años después, él señaló para el mismo periodo el saqueo de más de 100.000 mujeres e hijas (M. González, 3 mayo 1575). En 1575, Martín González se encontraba en Madrid y empezó pues a desarrollar una nueva estrategia discursiva. A partir del momento en que tuvo la oportunidad de dirigirse directamente a las autoridades máximas, el clérigo justificó y argumentó su demostración con ataques personales dirigidos específicamente a algunos conquistadores para dar mayor relieve a sus escritos y volverse más influyente. Por ejemplo en una carta escrita el 5 de mayo de 1575 denuncia a un tal: Hernan fustillo que [...]traxo [...] mas de 500 yndias [...] ruy diaz melgarejo [...] que [...] a tomado y quitado mas de 10000 yndias [...] tovadillo [...] a traydo en vezes mas de 3000 yndias (M. González, 5 mayo 1575). Su denuncia alcanza un punto álgido en la carta del 10 de mayo de 1575 , el documento se aboca a denunciar a todos los rancheadores vecinos de Asunción valiéndose de una enumeración de nada menos que de 288 personas.

Antes los escritos de Martín González, fray Bernardo de Armenta también había denunciado la deportación masiva de mujeres guaraníes para el servicio de los españoles. Este franciscano aparece en los documentos coloniales como una persona muy activa en las primeras empresas evangelizadoras, hasta tal punto que en la documentación quedó el apodo de Paí Zume ${ }^{2}$ que algunos grupos guaraníes le habían otorgado. Podremos pensar que entre el padre Armenta y los caciques regionales se llegó a crear una relación muy estrecha y el fraile en sus diferentes correspondencias pudo referirse a uno de los mayores problemas de la Provincia del Paraguay. Así que en una carta redactada en 1544, Bernardo de Armenta describe una práctica ya generalizada, en una época muy temprana para la Provincia del Paraguay, de robos y sacas de mujeres indígenas ${ }^{3}$.

El testimonio del fraile franciscano pone en evidencia la costumbre de deportar a las indias para el servicio de los cristianos añadiendo a su vez un nuevo aspecto: la reducción de las mujeres indígenas, consideradas ya en aquel momento como libres y vasallas del monarca, a la condición de esclavas. Volveremos sobre las consecuencias de las rancheadas y pues del cambio de categoría de las indias en una tercera parte.

Otro religioso del clero secular de gran influencia en el Paraguay, Francisco González Paniagua advirtió las autoridades indianas sobre la nefasta manía por parte de los españoles de robar las fuerzas procreadoras de las comunidades existentes en los alrededores de la ciudad de Asunción. El eclesiástico narra una práctica eficaz y organizada valiéndose de todas las categorías sociales para llegar a sus fines:

cada uno dellos enbiara 1 lengua y 2 moços a robar la tierra y a los capitanes para que se estubiesen entre los yndios en sus casas $15 \mathrm{o}$ 20 dias y a otro qualquyer soldado para que fuese 45 o 50 leguas la tierra adentro a tomar las yndias de grado o por fuerça a los yndios naturales bien o mal pagadas (González Paniagua, 17 febrero 1545).

El testimonio de Francisco González Paniagua denuncia la organización de rancheadas por parte de los oficiales reales quienes reclutaban lenguas o intérpretes y mozos o más bien mestizos para asegurar una captura importante de mujeres indígenas. La facultad linguística parece ser la clave de una descontrolada saca de mujeres durante la conquista del Paraguay, o sea que la deportación y la aculturación del indio pasaba esencialmente por medio de la lengua guaraní. Tanto el mestizo como el lengua podían ofrecer sus servicios solamente por el hecho de haber adquirido el conocimiento lingüístico del elemento vernáculo.

\section{El obispo quiere restituir los indios robados a sus pueblos originales}

Hay que esperar hasta el año de 1555 para que la suprema autoridad religiosa de la provincia entre 
en el debate. En efecto, desde su llegada en la ciudad de Asunción, el obispo franciscano Don Fray Pedro Fernández de la Torre no desarrolló una política de protección del elemento indígena, todo lo contrario. Entre 1558 y 1559, Martín González mandó al obispo y al gobernador varias quejas denunciando los malos tratos infligidos a los indios; y tanto el poder civil como el religioso contestaron al unísono rechazando todas las reivindicaciones del clérigo. Las posiciones expuestas en las cartas de Martín González le causaron muchas contrariedades y amenazas de todo tipo y en 1564 aprovechó la organización de una expedición a Santa Cruz de la Sierra para huir hacia el Perú. El contexto socio-histórico de estos mismos años no permitió mejorar la protección de las comunidades indígenas. Se observó en Asunción una inestabilidad poco común ya que fue un periodo marcado por el enfrentamiento público entre el obispo y el gobernador del momento Felipe de Cáceres. Quizás por ello, después del enfrentamiento entre las dos autoridades supremas, el mismo obispo De la Torre redactó en Asunción un documento de gran interés para nuestro estudio. La siguiente cita es muy ilustrativa de lo que señalamos:

Mande [...] diligençia sacar y buscar todas las yndias e yndios mugeres e ombres niños e niñas que fueron tan ynjustamente traydas e presos [...] los llevemos con nos para que sean rrestituydos a los maridos sus mugeres e a los padres e madres sus hijos e hijas e libertados los prisioneros como lo manda su magestad en las ordenanças de barçelona (P. Fernández de la Torre, 573).

En 1573, o sea catorce años más tarde, después de haber rechazado las demandas protectoras de Martín González, el obispo ordenó la restitución de los indios a sus pueblos de origen imponiendo por primera vez las Leyes Nuevas publicadas en Barcelona en 1542. Quizás el miedo a la condenación eterna haya operado un cambio de perspectiva ya que al parecer el obispo falleció un año después en el puerto portugués de Santos, capitanía de San Vicente, Brasil.

\section{Los Estragos de la Conquista en la Provincia del Paraguay}

Las rancheadas, comolopudimos ver anteriormente, provocaron un ocaso demográfico importante. Las series de deportaciones humanas hacia Asunción y hacia otros pueblos, en particular a Ciudad Real en la región del Guaira, operaron un cambio rotundo, una ruptura en las relaciones hispano-indígenas. El sistema de encomienda impuesto, aunque tardíamente en el territorio paraguayo, de cierto modo legitimó el robo de indígenas como única fuente de riqueza y recompensa para los conquistadores. El juego de alianzas políticas y guerreras entre los europeos y los caciques guaraníes se vio trastornado, completamente alterado. En esta última parte seguiremos enfocándonos en las rancheadas pero dirigiendo nuestra reflexión hacia las consecuencias del rapto masivo de mujeres en la sociedad colonial. Si las prácticas de los actores coloniales ocupan un espacio importante en nuestro trabajo, no obstante el discurso de los cronistas e informantes no deja de ser primordial a la hora de entender los procesos de deportación indígena.

\section{Fugas y revueltas por malos tratos: carios, chiriguanos, itatines y tupis}

La primera reacción de algunos indios guaraníes frente a la imposición del sistema de encomienda fue alejarse del infierno asunceño en donde se usaban indios como mano de obra esclava. Para aquellas personas la huida hacia el monte representaba la única manera de preservar su vida sin sufrir tormentos. Las redes relacionales indígenas se vieron de nuevo modificadas, a consecuencia de ello asistimos a varios conflictos indígenas y probablemente a ritos de antropofagia. Si los carios no pudieron emprender revueltas de gran envergadura, otras comunidades indígenas que no estaban directamente vinculadas con los recién llegados causaron muchas perdidas humanas a los españoles. Martín González que bien podría ser el cronista indigenista de esta conquista, ya que sus escritos refieren acontecimientos precisos de las acciones indígenas en todo el territorio, describió en cartas redactadas en 1574 la venganza de los indios tupis en territorio portugués, el religioso comentó que: "amagados de los asaltos passados y guerras y crueldades que contra ellos avian hecho, mataron 9 spañoles de la compañía del dicho Ruy Diaz y obra de 800 yndios poco mas o menos" (M. González, 2 junio 1574). Los testimonios provenientes de los diversos archivos concuerdan en señalar que cada expedición hecha por los españoles después de 1556, afrontó peligrosos ataques indígenas. Es así como nuestro cura, contaba y señalaba: "que no son señores los Españoles de salir 4 leguas fuera de la Asumpçion" (M. González, agosto y noviembre 1574). Las diferentes campañas de "pacificación" de los movimientos sediciosos indígenas tuvieron forzosamente grandes y graves consecuencias en la naciente sociedad colonial. Los testimonios de las luchas externas para mantener el establecimiento español en la ciudad de Asunción dan una clara imagen de la fragilidad del proyecto de conquista en estas tierras. Si Martín González y otros testigos 
enfatizan en sus escritos el temor y el miedo español a la agitada tierra adentro, ellos mismos pusieron de realce otros peligros quizás aún más problemáticos ya que se sitúan en el seno mismo de la sociedad: los mestizos.

\section{El mestizo: fruto de los procesos de cuñadazgos y de rancheadas}

Según las cifras avanzadas por el clérigo, la deportación de cien mil mujeres en un periodo de veinte años, básicamente guaraníes, causó el mayor ocaso demográfico de población indígena, de todo el territorio. El proceso de rancheadas, como lo señalamos anteriormente, constituyó el fenómeno de aculturación más importante en el siglo XVI. Sin embargo, en las diferentes cartas dirigidas al Consejo de Indias los testigos de aquel entonces se declaran preocupados por la presencia en la sociedad colonial de numerosos hijos de las criadas indígenas, los llamados mancebos de la tierra ${ }^{4}$. El mancebo o mestizo fue siempre un agente activo en las deportaciones indígenas, esta nueva categoría de personas en la sociedad colonial paraguaya surgió del proceso de deportación y de concentración de mujeres indígenas en Asunción. Encontramos pues en las fuentes, referencias a la ayuda de los mestizos en las rancheadas. Nuestro "cronista oficial" declaró en 1575 que: "Otros españoles an enbiado a sus hijos mestizos aunque ellos no a ydo y an traydo munchas" (M. González, 10 mayo 1575). En efecto, los mancebos de la tierra, al superar a sus padres en cuanto al uso de las lenguas autóctonas difundidas en todo el territorio, así pudieron sacar más fácilmente a las mujeres de los pueblos de indios. Este aspecto, sin embargo, no es lo que predomina en la presentación de la categoría de mestizo en el Paraguay del siglo XVI. Como ya lo habíamos señalado el temor al mancebo parece en la documentación temprana superar su sentido de aliado. El clérigo Martín González presenta en sus escritos la amenaza de una categoría colonial emergente:

Restamos de advertir a Vuestra Alteza que en sola la çiudad de la asumpçion ay cinco mill mestizos poco mas o menos hijos de españoles y yndias y mas de los tres mill dellos seran de 18 años arriba, y mugeres avra casi otras cinco mill mestizas / y estos mestizos avra quinze años poco mas /o menos que procuraron de querer matar a sus padres con aver entonçes menos / y despues aca han querido alçarse con la tierra dos o tres vezes como lo han dichos los que de nuevo han venido de poco aca / y esto con yntento de juntarse estos mestizos con los naturales que son sus tios y parientes, y desto fuy yo avisado de los yndios por la affiçion que me tenian, y entonçes se puso remedio en ello / y si entonçes siendo los españoles muchos demas de .600. arriba, y los mestizos pocos se atrevian ha intentar esto, que se podra presumir ni esperar ahora, no quedando en la çiudad de la asumpçion mas de dozientos y ochenta españoles y los çiento dellos inutiles y los demas ya viejos y los mestizos como dicho tengo que passaran mas de tres mill que podran tomar armas (M. González, 3 mayo 1575).

Esta larga cita nos invita a reflexionar sobre el aislamiento de este territorio que llamamos en nuestro estudio Paraguay. Las pocas expediciones españolas, los intentos desafortunados de vincularse con otras provincias, transformaron ipso facto el Paraguay en una provincia compuesta principalmente de mestizos ya en una época muy temprana. Además del gran número de mestizos en el meollo de la conquista, se destaca otro aspecto primordial: Martín González presenta en esta cita una categoría más inclinada hacia sus orígenes indígenas. La natural inclinación del mestizo hacia las costumbres indígenas, según las cartas del eclesiástico, llama la atención en cuanto al poder argumentativo del religioso. Tanto el indígena como el mancebo parecen sufrir de la dominación y de los malos tratos infligidos por los españoles, Martín González no descarta la idea de una unión de las dos categorías y por consiguiente de la destrucción del sistema colonial en las tierras del Paraguay. Frente al mayor problema de la provincia, el representante de la Iglesia, se presenta como la única solución para pacificar y desarrollar las empresas coloniales en este territorio.

Después de haber tratado la condición del mestizo o mancebo en el Paraguay de aquel entonces, podríamos abarcar la última categoría resultante de las rancheadas: la servidumbre indígena.

\section{De indio a esclavo}

Considerar la noción de esclavos en el contexto socio-histórico del Paraguay colonial nos interesa directamente para avanzar en nuestra reflexión. No entraremos en el estudio del indio libre transformado en esclavo de guerra durante las diferentes batallas ocurridas a lo largo de la conquista. Sabemos que cualquier indio que se oponía al avance de los españoles podía perder su libertad según la legislación española ${ }^{5}$. No trataremos en esta parte de los numerosos indígenas privados de sus derechos 
por defender sus territorios ancestrales. Sin embargo, hemos decidido enfocar nuestra atención en el análisis del cambio ilegal de categoría de indio a esclavo. El proceso de deportación masiva de mujeres indígenas posibilitó la rápida transformación de mujeres criadas en esclavas meros objetos de compra y venta en el mercado interno como externo a Asunción. Antes de referirnos a nuestro corpus de fuentes primarias referentes al problema de la servidumbre indígena, recordemos que la legislación española y más específicamente las Leyes Nuevas publicadas en Barcelona en 1542 impidieron cualquier cambio de estatus del indígena. En una carta redactada en 1558, el clérigo Martín González vuelve sobre la imposición del derecho español como argumento decisivo en la protección del indio ${ }^{6}$.

La difusión de las leyes protectoras para los indígenas efectuada por Martín González no tuvo el efecto esperado. Antes otros religiosos habían anticipado el problema de la servidumbre indígena, pero los conquistadores y vecinos de la ciudad de Asunción siguieron actuando sin respetar la reglamentación indiana como podemos observar en el testimonio siguiente, redactado por el clérigo Francisco González Paniagua:

A se usado despues de la prisyon del governador entre los cristianos desta tierra un trato y mercançia de bajo de muy gran cautela muy en ofensa de Dios nuestro señor daño y perjuyzio de la conçiencia de su magestad y contra sus rreales provisyones y es las yndias libres y naturales de la tierra venderlas como si fuesen esclabas venydas de Guynea desta manera yo vendo una casa y una rroça que puede valer en publica almoneda 20 ducados y no mas y digo al que la vendo fulano y os tengo de dar esta casa y rroça y vos // me aveys de hazer una / obligaçion de 40 ducados en que solamente fue en la casa y rroça y porque estas 2 pieças no valen tanto con mucha cantidad que de por convenençia entre vos e [...] que os dare 1 yndia Guarani de las de la tyerra $[. .$.$] que ya sabe que son libres$ y no se pueda vender [...] Otro an que algo mas liçito y en esto por la neçesydad de la tierra el qual en el se remediasen de serviçios y bosque en esta tierra a estaban desnudos de algun vestido que yo tengo una capa y / otro una yndia truecase la capa por la yndia por la neçesydad que el uno tiene de la capa y el / otro de la yndia por color por vender la yndia syno el serviçio della pasando del uno en el otro con la misma libertad que antes tenya / tanbien se a usado dar e trocar una esclava herrada por una yndia libre / y en este caso no solamente an errado los legos pero aun religiosos (F. González Paniagua, 3 marzo 1545).

Francisco González Paniagua retrata el proceso mercantilista del tráfico de esclavos en la ciudad de la Asunción. Frente al alto número de mujeres traídas en las diferentes campañas de deportaciones, los vecinos parecieron deshumanizar a las indias convirtiéndolas automáticamente en piezas esclavas. Las mujeres guaraníes pudieron ser objeto de transacciones más o menos complicadas, o sea la venta de indias llegó a satisfacer las necesidades de la vida cotidiana como la posibilidad de adquisiciones de cualquier otro bien. Podemos apreciar aquí una referencia clara a la equiparación de las mujeres indígenas libres con las esclavas africanas específicamente de Guinea, origen por excelencia de los esclavos africanos deportados hacia América. La presencia de esclavos africanos aparece en muy pocos documentos ${ }^{7}$. El contexto socio-histórico del Paraguay nos guía más bien en una presencia importante de indios esclavos de guerras. $\mathrm{La}$ generalización del tráfico ilegal de mujeres indígenas llegó a tal extremo que los mismos religiosos usaron como moneda corriente la india guaraní. La venta de esclavas pudo ser más fructuosa desarrollando verdaderas redes ilegales de tráfico humano. Según los documentos, Asunción se convirtió en un campo de concentración de esclavas con el fin de alimentar un mercado de esclavos existente en el puerto portugués de São Vicente en la costa del Brasil. En el año de 1556, dos testigos antagónicos de la provincia mandan cartas a las autoridades indianas describiendo el proceso de compra y venta de esclavas del Paraguay para São Vicente ${ }^{8}$.

La servidumbre ilegal de las indias guaraníes constituye un argumento poderoso en las distintas quejas y denuncias de las malas actuaciones de algunos de los conquistadores. El antagonismo entre Domingo Martínez de Irala y Diego Tellez de Escobar aparece en una lucha epistolar sin fin en la cual la protección del indígena se vuelve en un pretexto para atacar y desestabilizar al enemigo. Los problemas expuestos por los dos conquistadores ponen de realce la necesidad de enriquecerse por todos los medios posibles, incluso la venta de indias vasallas del monarca español a los portugueses quienes aplican otra legislación en cuanto a la libertad de los indios. Estas relaciones basadas en intercambios ilegales entre los españoles de Asunción y los portugueses de São Vicente parecen ser motivos de preocupación para las autoridades indianas.

Decidimos cerrar este rastreo, que permitió evaluar la amplitud de las deportaciones y de la esclavitud 
indígena en la provincia del Paraguay durante el siglo XVI, con una última intervención del clérigo Martín González que hace eco a las palabras del gobernador Francisco Ortiz de Vergara citadas en la introducción:

Ansi mismo algunos de los españoles como tienen yndios en sus casas para servirse dellos, como adelante dire, los castran, a unos porque han venido a entender que tienen copula carnal con estas yndias y a otros porque no la tengan / y como los dichos naturales no alcançan oro ni plata para dar tributos lo dan del sudor de sangre con muy grandes trabajos insoportables [...] y assi los hazen estar y trabajar como si fuessen propios esclavos, o negros comprados [...] quando algun yndio no quiere dar la muger o hija que le piden echanlo en el çepo / o grillos hasta que la trae (M. González, 3 mayo 1575).

La falta de minas y de riquezas minerales no mejoró las condiciones de vidas del indio que por aquel entonces sufrían grandes estragos en las minas peruanas del Potosí y novohispanas de Zacatecas. La lógica colonial que buscaba imponer el trabajo bajo apremio a los habitantes originarios pareció suplantar el respeto a las diferentes reglamentaciones reales. En Paraguay, la servidumbre de los nativos americanos estuvo frecuentemente vinculada a la deportación de seres humanos y al enriquecimiento personal equiparando, a pesar de las prohibiciones, la categoría social del indio vasallo de su majestad a la condición de esclavo africano. Cuando se hizo público este asunto a partir de 1544, la única repercusión fue el nombramiento y la llegada a la ciudad de Asunción en 1556 de Don Fray Pedro de la Torre como obispo y protector de los indios.

\section{Conclusión}

Las deportaciones indígenas y más específicamente las sacas de mujeres, fueron fenómenos que causaron la muerte de miles y miles de personas. El proceso de rancheadas originó igualmente grandes estragos en los indios sobrevivientes, así como la aculturación masiva de los nativos en la Provincia del Paraguay ya a partir de 1541. Los conquistadores y vecinos de Asunción habiendo padecido numerosos fracasos en las diferentes campañas de exploración del territorio, en primer lugar a la famosa Sierra de la Plata, tuvieron como única esperanza la llegada de nuevos contingentes para desarrollar la conquista del Paraguay. A pesar de algunos socorros mandados desde España, los europeos nunca pudieron satisfacer su sed de enriquecimiento en estas tierras y encontraron como único modo de existencia el avasallamiento de las poblaciones autóctonas. El cambio drástico que impuso la colonización española en Paraguay pareció afectar en primer lugar a las mujeres indígenas quienes recibieron el mayor impacto. Finalmente, los procesos abarcados -tales como el cuñadazgo, las rancheadas y el avasallamiento de los indioscaracterizan el contexto socio-histórico de nuestro estudio que pone de realce una lógica colonial ilícita pero aceptada y ampliamente extendida en el Paraguay del siglo XVI.

\section{Referencias Citadas}

\section{Siglas}

AGI: Archivo General de Indias (Charcas).

AHN: Archivo Histórico Nacional.

ANA: Archivo Nacional de Asunción.

AGI, Charcas, 40. Anónimos. Memoria de ciertos autores de las cosas mal hechas que dize que haze Domingo de Yrala. Asunción siglo XVI.

AGI, Charcas, 42. Anónimos. Memorial de los vecinos de Asunción, 4 de julio de 1545.

AGI, Justicia, 1131. Pieza 15 del proceso de Alvar Núñez Cabeza de Vaca. Carta de Fray Bernardo de Armenta del 10 de Octubre de 1544. Asunción.

AGI, Charcas, 42. Carta de P. De Orantes del factor sobre la prisión de los Indios Agaces. Asunción 1544.

AGI, Charcas, 143. Carta redactada por el clérigo M. González del 7 de noviembre de 1558. Asunción.
AGI, Charcas, 143. Traslado de las Leyes Nuevas por el clérigo M. González en su carta del 7 de noviembre de 1558. Asunción.

AGI, Charcas, 143. Carta M. González del 2 de junio de 1574. Ponta Delgada Isla de San Miguel Azores.

AGI, Charcas 143. Carta de M. González, agosto y noviembre de 1574. Madrid.

AGI, Charcas, 143. Carta de M. González 3 mayo 1575. Madrid.

AGI, Charcas, 143. Carta de M. González 5 mayo 1575. Madrid.

AGI, Charcas, 143. Carta de M. González 10 mayo 1575. Madrid.

AGI, Justicia, 1131, Pieza 15. Carta del clérigo F. González Paniagua del 17 de febrero de 1545. Asunción.

AGI, Justicia, 1131, Pieza 15. Asunción. Carta del clérigo F. González Paniagua del 3 de marzo de 1545. Asunción.

AGI, Patronato, 187, R. 22. Martinez de Irala, D. Relación breve con parecer del Gobernador de la Provincia del Rio de 
la Plata por su Majestad para el Ilustrísimo Señor Marques de Mondejar del Consejo de su Majestad y su presidente en el Consejo de las Indias. Asunción 1556.

AGI, Patronato, 29, R.19. Carta de Francisco Ortiz de Vergara 1565. Asunción.

AGI, Asunción Justicia, 1131. Testimonio del interprete Juan Perez en la pieza 12 del proceso de Alvar Nuñez Cabeza de Vaca. Asunción siglo XVI.

AGI, Charcas, 40. D. Tellez de Escobar, memoria de las cosas acaecidas después de la venida de Cabeza de Vaca y agravios que dice que hace Yrala. Asunción 31 mayo 1556.

AHN, Colección Documentos de Indias 24, N.17. Carta de M. González del 1 de julio 1556. Asunción.

ANA, Sección Nueva Encuadernación, Volumen 307, Documento 76. Carta del Obispo Don Fray Pedro Fernandez de la Torre 3 abril 1573. Asunción.

\section{Fuentes publicadas}

Cortesão, J. 1951. Jesuitas e Bandeirantes no Guairá (1549-1640). Vol. I Biblioteca Nacional, Rio de Janeiro.

Melià, B. 1993. El Guarani Conquistado y Reducido. Biblioteca Paraguaya de Antropología Vol. 5, Centro de Estudios Antropológicos Universidad Católica "Nuestra Señora de la Asunción", Asunción.

Roulet, F. 1993. La Resistencia de los Guarani del Paraguay a la Conquista Española [1537-1556]. Editorial Universitaria Universidad Nacional de Misiones, Posadas.

Ruiz Montoya, A. 1876. Vocabulario y Tesoro de la Lengua Guarani, o mas Bien Tupi. Maisonneuve et Compagnie, Paris.

Susnik, B. 2011. El Rol de los Indígenas en la Formación y en la Vivencia del Paraguay. Intercontinental Editora, Asunción.

Susnik, B. 1965. El Indio Colonial del Paraguay. Museo Etnográfico Andrés Barbero, Asunción.
${ }^{1}$ Mbae cuña oyapó? Que muger lo hizo? (Ruiz Montoya 1876:70)

${ }^{2}$ Pai Zume: referencia guaraní del apóstol Santo Tomas en América.

3 "Tanbien entre los cristianos desta provincia se a ussado y usa que despues de aver avido las yndias que mas pueden de los yndios de la tierra para su servycio las tales yndias las tornan luego a vender y contratar por muy eçesivos precios unos cristianos entre otros como si fuesen esclavas" (Carta de Fray Bernardo de Armenta 10 de Octubre de 1544).

${ }^{4}$ Los Mancebos de la tierra: "Parti de ciudad de la Assumpcion el año de 1565 a 28 dias del mes de septiembre i saque 120 españoles de guerra y 30 mancebos montañeses que en otras partes de yndias llaman mestizos pero son tan hombres de bien en aquellas provincias de que no conviene llamarles mestizos sino del nombre de que ellos se precian que es montañeses" en Carta de Francisco Ortiz de Vergara 1565.

5 "ansi mesmo parecida contra ellos en reveldia conforme a derecho y si por el paso paresçiere que se deve de hazer se den por enemigos y se les haga guerra y se den por esclavos conformandose vuestra señoria con lo que su magestad mando sus rreales ynstruçiones" (Carta de P. De Orantes del factor sobre la prisión de los Indios Agaces).

6 "Yten ordenamos y mandamos que de aqui adelante por ninguna causa de guerra ny otra alguna aunque sea por titulo de rebelion ni por rescate ny de otra manera no se pueda hazer esclabo yndio alguno y queremos que sean tratados como vasallos nuestros de la corona de castilla pues lo son I. [...] Como avemos mandado probeer que de aquí adelante por nynguna via se hagan los yndios esclavos ansi en los que hasta aqui se an hecho contra razon y derecho y contra las provisiones e ynstruiçiones dadas / ordenamos y mandamos que las audiençias llamadas las partes sin tela de juyzio sumaria y brevemente sola verdad sabida los pongan en libertad si las personas que los tubieren por esclabos no mostraren titulo como los tienen y poseen ligitimamente y porque a falta de personas que soliçiten lo suso dicho los yndios no queden por esclabos ynjustamente mandamos que las audiençias pongan personas que sigan por los yndios esta cabsa y se paguen de penas de camara y sean honbres de confiança y diligençia I" (Traslado de las Leyes Nuevas por el clérigo M. González en su carta del 7 de noviembre de 1558).

${ }^{7}$ La presencia de esclavos africanos en el Paraguay de la conquista : "Otro si estando un regidor que se dize Rodrigo Gomez en un pueblo de indios vio una carta que llebaban unos esclabos a uno destos robadores que andan por la tierra que se llama Juan de Quintana para que el con aquellos esclabos a quien los yndios tienen gran temor y les tomasen a los yndios çiertas de sus mugeres y si no se las quisiesen dar los amenazasen con ellos esta carta vieron otras 2 personas que quedan alla que se llama el uno Juan Duran y el otro Brabo" en Anónimos, Asunción siglo XVI. AGI, Charcas, 40.

8 "En este tiempo vino un Portugues de la costa del Brasil que truxo algun hierro y herramyentos para contratar en la tierra y el mismo Domingo de Yrala le dio yndios e yndias de la tiera truxo de aquel hierro que el traya y dio lugar que sacaba del pueblo e de la tierra yndios e yndias para llebar al Brasil a tierra del Rey de Portugal donde los registraron y quytaron y los tenyan por esclavos. Y de esta manera vinyeron otros 2 o 3 Portugueses a quyen Domingo de Yrala hizo lo mesmo dandoles lugar que sacasen los naturales de la tierra e vendiesen en Portugal" (Tellez de Escobar Memoria de las cosas acaecidas después de la venida de Cabeza de Vaca y agravios que dice que hace Yrala). 